\title{
9 Surveillance, intelligence and ethics in a COVID-19 world
}

\author{
Jessica Davis
}

\section{Introduction}

In the initial weeks and months of the COVID-19 pandemic, states grasped at any possible tools to help them battle the economic, health and human impacts of the disease. The severity of the crisis led states to use, or consider using, any tools at their disposal, including those that had previously only been used for national security applications. The pandemic struck at a time when personal technology (such as smartphones) and surveillance technology uses were at an all-time high and states looked to both of these types of technology to stop the spread of the virus. The use of intelligence and surveillance tools that were once largely purview of security, intelligence and law enforcement being used for pandemic surveillance represents the lengths that many states have been willing to take to stop the spread and limit the damage (Davis 2020).

States leveraged personal technologies primarily for contact tracing purposes, or to provide notifications to users of possible exposure to COVID-19. However, some states sought to use tools developed for national security purposes (such as counter-terrorism or counter-espionage), which often exploit personal technology data, to help contain the virus. Other surveillance technologies, such as closedcircuit cameras and facial recognition software, were also deployed to combat the virus. The use of these tools and techniques, once largely the purview of security, intelligence and law enforcement, represented the extraordinary lengths that many states took to stop the infection. These efforts involved collecting data on citizens from cell phones, financial transactions and social media intelligence and combined it with or exploited it for health data, raising significant concerns about privacy and civil liberties.

The nature of the pandemic has in part driven this reliance, or at least turn, to technology and national security surveillance techniques. Traditional contact tracing works well when transmission requires sustained, intimate contact, but when transmission can occur through limited exposure and the virus can be spread by asymptomatic people, traditional models of health surveillance may fall short (Berman, Fowler, and Roberts 2020). In the first six months of the pandemic, however, the disease has proven largely impervious to these efforts. Many of these technologies were envisioned to be used in a targeted way, as a means of

DOI: $10.4324 / 9781003164197-13$ 
tracing close contacts and the source of infection. In many cases, the ability to trace specific cases has proven only partially successful due to the widespread infection rates many countries experienced.

Of course, public health surveillance and national security surveillance are two distinct paradigms with different values and governing norms (Berman, Fowler, and Roberts 2020,1). For the purposes of this chapter, I will make a distinction between the two by using the terms national security surveillance to describe technologies and techniques of surveillance usually associated with law enforcement, intelligence, and security services, and health surveillance to refer to more traditional modes of the collection of health, infection and pandemic-related information. National security surveillance and public health surveillance also have very different purposes and applications, differences that have an impact on any discussion of intelligence, ethics and surveillance during a pandemic. Health surveillance is cooperative, minimizes data collection and limits subsequent use (Berman, Fowler, and Roberts 2020, 1). National security surveillance operates coercively, maximizes data collection, and in some countries, there are few limits on use of lawfully collected data (Berman, Fowler, and Roberts 2020, 1). In these two forms of surveillance, the role of consent, scope of collection and subsequent use are all different and differently restricted (Berman, Fowler, and Roberts 2020, 19).

This chapter will look at the surveillance methods used by states in an effort to stop the pandemic and discuss the ethical implications of those efforts, drawing on literature in the field of ethics of surveillance and bio-surveillance. This analysis will be structured on two frameworks for the ethical collection and use of intelligence by Bellaby and Omand (Omand 2006; Bellaby 2012).

\section{National security surveillance in the first six months of the pandemic}

In the first six months of the pandemic, a number of states discussed the possibility of exploiting national security surveillance tools to fight the pandemic. In most cases, states opted to forgo these efforts due to a host of practical, privacy, legal and technological challenges. However, to curb the spread of COVID-19 some countries have been moving to implement technologies to monitor and surveil their citizens and provide early warning of infection and spread. Indeed, the policy response to the COVID-19 pandemic has been to categorize and compare a mix of policy tools that have been deployed by governments, some of which have been national security surveillance tools. In almost every country, the COVID-19 pandemic has seen an unprecedented use of technology (The Soufan Center 2020; Dunlop, Ongaro, and Baker 2020; Berman, Fowler, and Roberts 2020, 1).

In a survey of 56 countries conducted between March and August 2020, 45 $(80 \%)$ were using technology to track COVID-19 outbreaks. Of those 45 countries, another $18(40 \%)$ were using national security surveillance technology to track infected individuals, individuals required to self-quarantine, or to surveil their population writ large for signs of infection or compliance with local regulations, illustrated in Figure 9.1. 


\title{
USE OF TECHNOLOGY FOR COVID19 SURVEILLANCE
}

\author{
No technology used \\ $\square$ Use of technology (personal) \\ Use of national security surveillance technology
}

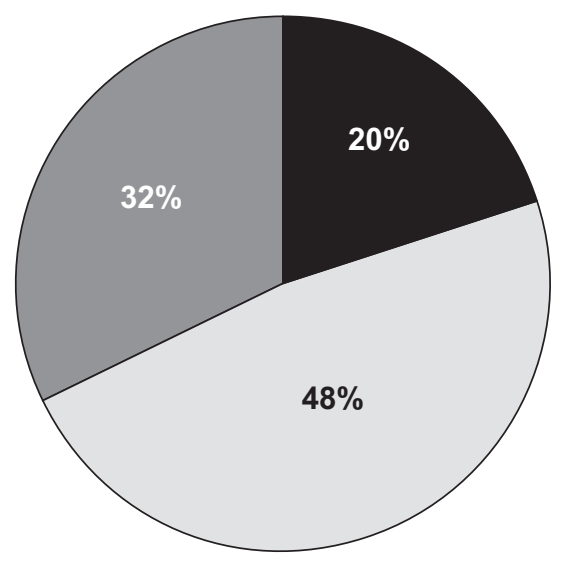

Figure 9.1 Use of technology for COVID-19 surveillance.

These technologies primarily involved facial recognition and closed-circuit cameras, location monitoring, financial transaction and social media intelligence and other (unspecified) tools that were developed to combat terrorism but that had been re-deployed to combat the pandemic. For example, in the United States, Army technology developed to combat terrorism was deployed to help monitor the spread of COVID-19. The Army used social media, news media, blogs and government sources to create actionable data to be used for force protection, including information about COVID-19 derived from all of these sources (Brading 2020).

In another example, in March 2020, Israel invoked emergency powers to use cell phone tracking data to retrace the movements of those believed to be infected and to implement quarantines. The data had previously been acquired by the Israeli Security Agency (colloquially known as Shin Bet) for counter-terrorism purposes. The disclosure of the programme raised concerns that it violated the privacy of Israeli citizens and that granting of emergency powers would open the door to future abuses (Sachs and Huggard 2020). The utility of these surveillance tools during the COVID-19 pandemic is questionable, as in September 2020, Israel announced that it was undertaking another three weeks of lockdown (at least) due to rising infection rates (BBC News 2020b). 
Israel was not alone in deploying existing national security surveillance tools for pandemic surveillance. In Pakistan, a secret surveillance system that was used to track terrorist suspects by the Inter-Services Intelligence Directorate (ISI) (Pakistan's primary intelligence service) was deployed to combat the pandemic. While few details have been released regarding its actual application for pandemic surveillance, the system has geo-fencing and telco-tracking mechanisms and allows for the monitoring of confirmed patients and potential virus carriers. The system is also reported to track movements and be able to listen to private phone conversations as part of its efforts to monitor possible symptoms (Shairani 2020).

While counter-terrorism tracking programmes have been deployed in at least two countries, other states have deployed national security surveillance tools more selectively in their bid to stop the spread of the virus. For instance, South Korea used mobile technology against the outbreak to facilitate contact tracing people who tested positive for the virus were asked to describe their recent movements, and the state facilitated this process by using Global Position System (GPS) phone tracking, surveillance camera records and credit card transactions (McCurry 2020). For its part, Hong Kong opted for physical location monitors in the form of wristbands that linked to smartphones to provide location-tracking services to help enforce quarantine requirements for new arrivals (Sharwood 2020).

The use of closed-circuit cameras and facial recognition software was also deployed in the early stages of the pandemic. These efforts were aimed at detecting possible signs of infection and to detect compliance with quarantine or regulatory requirements. In China, facial recognition technologies that can detect elevated temperatures in a crowd were deployed and cameras were used to flag and identify citizens not wearing a mask. These surveillance activities were described by the state as part of a response during an "extraordinary time" that requires extraordinary measures (Kuo 2020). However, Chinese citizens noted that the same justification was used in deploying other surveillance technologies in advance of the Olympics, technologies that have since become a permanent feature in China (Kuo 2020). In Russia, closed-circuit cameras were used to enforce lockdown while in France, surveillance cameras were used to check adherence to rules (BBC News 2020; Rosemain 2020). As part of a three-month experiment, artificial intelligence-powered technology checked for adherence to local rules in place during the pandemic, such as wearing masks and adhering to physical distancing requirements (Rosemain 2020).

The use of national security surveillance technologies and tools for pandemic surveillance has been relatively constrained to a small number of countries. Many other states have adopted personal technologies like applications installed on smart phones for pandemic surveillance, monitoring and alerts, but for the most part these applications have been limited in scope and have privacy protections in place. While many states initially considered using more invasive and targeted measures for pandemic surveillance, privacy, legal and regulatory and practical constraints have limited this practice. In essence, while the tools of national 
security appealed during the initial phase of the pandemic, the actual nature of how the virus spreads, along with the rate of infection, also worked to preclude the use of national security surveillance technologies.

\section{Thinking ethically about national security surveillance during the pandemic}

Times of crises and emergencies often lead states to consider or implement legislation, regulation and practices that they otherwise would not in the name of national security. Even though there are almost certainly critics of these practices, in many cases, public support is often on the side of governments implementing these changes in the name of national security. States of emergency may also stifle or silence critiques of these practices. However, the COVID-19 pandemic is relatively unique in terms of national and international emergencies: it is far lengthier than most, which creates space for critique and re-considering practices adopted early during the pandemic. It also allows for the consideration of best practices for the duration of the pandemic and future emergencies.

Intelligence studies have furnished us with two very useful frameworks for investigating the ethics of the practice of intelligence, which is a collection of activities such as information gathering, exploitation, all-source analysis and covert action (Herman 2013). Omand's framework calls for intelligence to be collected and analysed using six main principles:

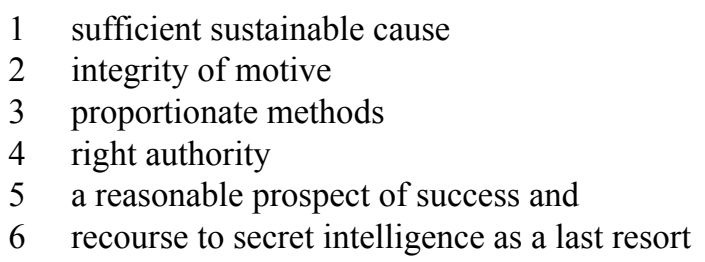

(Omand 2006, 618-19)

Bellaby's framework has similar elements and a few key differences. Bellaby argues that the practice of intelligence should be conducted along six principles as well:

1 just cause

2 legitimate authority

3 intention (intelligence should be used for the intended purpose)

4 proportionality (the harm caused outweighed by gains)

5 as a last resort and

6 targets should be discriminate (between legitimate and illegitimate)

(Bellaby 2012, 109)

Both frameworks have significant overlap in the principles they espouse, including just or sufficient cause, proportionality, intentionality, legitimate authority and 
turning to intelligence as a last resort. They differ in that Omand also includes the proposition that intelligence activities should only be undertaken when they have a reasonable prospect of success, while Bellaby proposes that targets of intelligence collection should be discriminate, in that some targets are legitimate, while others are illegitimate. For instance, it could be argued that mass surveillance breaches this principle because it does not discriminate between targets - everyone is a target of the intelligence collection mechanism.

In terms of using intelligence and surveillance during the COVID-19 pandemic, the cause can certainly be justified or found to be sufficient. As of September 2020, at least a million people had died worldwide from the virus, and millions of others had fallen ill, some with effects lasting in excess of six months and the economic effects of the pandemic have also proven significant (Yong 2020). These simple measures only scratch the surface of the pain and suffering that COVID-19 has caused. As such, using intelligence and national security surveillance to combat the pandemic could certainly be justified and be found proportionate as well in many societies. The proportionality question, however, is an essentially contested one and one that will differ from society to society depending on the importance that is placed on privacy.

The question of the legitimacy of authority of using intelligence and national security surveillance tools and techniques for pandemic surveillance is an interesting one and one that has already been breached. In the Israeli case, the legal foundation for the data set was for counter-terrorism and could not easily be transferred to pandemic surveillance. This lack of just authority resulted in a ban on the use of some of these tools until new laws are passed (BBC News 2020a). In Pakistan's case, the lack of legitimate authority does not seem to have stopped the ISI from employing its tools and techniques, a clear violation of the ethical principles of intelligence.

In the context of a global pandemic, the idea that intelligence and national security surveillance could be used as a last resort is an interesting one. Many tools exist that could facilitate contact tracing and population monitoring other than those employed by national security and intelligence agencies. In fact, most states have chosen to employ those tools rather than use their more contested tools for pandemic surveillance. However, if a vaccine for the virus proves illusive or only partially effective, states may increasingly be tempted to employ these tools and they may in fact be justifiable as a last resort.

The differences between the two ethical frameworks presented here are also worth considering. Omand argues that intelligence should only be undertaken when it has a reasonable prospect of success. In the case of COVID-19, early results from surveillance practices have demonstrated (particularly in the case of Israel) that the deployment of national security surveillance has not been successful. This is largely the result of the specific nature of the virus - it is easily transmitted and can be transmitted by asymptomatic people. For its part, most national security surveillance systems are targeted surveillance systems, most easily deployed and most useful against a set number of targets. Surveilling an entire population for possible signs of infection is something better left to health surveillance technologies and techniques. 
Finally, Bellaby argues that targets of surveillance and intelligence practices need to be discriminate, meaning that there needs to be a difference between legitimate and illegitimate targets. In many of the cases of national security surveillance deployed against COVID-19, this distinction has not been made. Instead, these tools have been deployed in the faint hope that they can provide some assistance for states fighting the pandemic. They have failed to distinguish between legitimate and illegitimate targets. However, this principle is perhaps of use in the future, if the scenario described earlier (no vaccine, or a minimally effective vaccine), and in a situation where a state has low levels of virus transmission. In that case, then some of the national security surveillance tools (such as enhanced location monitoring) could prove useful for reducing the spread of the virus and enforcing quarantine. In this instance, it would be critical to differentiate between legitimate targets of surveillance (perhaps those suspected of infection and unwilling to comply with quarantine) and those not (healthy or quarantineabiding individuals).

In addition to this framework, I also propose that in the case of health surveillance (particularly when done by national security agencies, or using national security surveillance tools and techniques), that transparency is a critical element. The authority for national security agencies to collect and use data - and the use of techniques and methods should not come as a surprise to citizens of democratic state. In the current case, the enemy is a virus, not an adaptive adversary, so the need for secrecy about specific methods may exist, but actual collection and use of information should be transparent and open to democratic debate (Davis 2020). Civil liberties should not be abandoned quickly or easily, even in the face of a global pandemic. Instead, any sacrifices made should be done by considering the ethics of the proposed action and balancing the welfare of individuals and the population writ large.

Consistency of use is another critical consideration. Indeed, in talking about the use of intelligence for counter-terrorism, Omand notes that there are worries over the wider uses to which information derived from information technology might be put (Omand 2006, 616). While all the propositions proposed in these frameworks are important, the consistency of use of data is one of the most important propositions in terms of ensuring ethical use of intelligence collected to combat the pandemic. Data must be used in a manner consistent with how and why it was collected (Davis 2020). These concerns should be central during the pandemic and any discussion of using national security surveillance. Consideration needs to be given to what will happen to the information, how long it will be retained for, who will maintain (and have access to) the data and its ultimate destruction. Information collected for public health can result in stigma, embarrassment and discrimination (Berman, Fowler, and Roberts 2020, 24). Discrimination based on health status is a very real concern and one that will only grow if an effective vaccine is not found.

A particular problem with using national security surveillance for pandemic surveillance is the aggregation problem. While an individual piece of information 
is not useful, in aggregate, they reveal intimate details of life (Berman, Fowler, and Roberts 2020,23). One single data point is not that useful; but a comprehensive record of what a person purchased over a sufficient period of time will reveal intimate life details (the whole adds up to more than sum of its parts) (Berman, Fowler, and Roberts 2020,23). The aggregation problem needs to be part of the ethical framework for considering the use of national security surveillance tools and techniques for pandemic surveillance.

In considering the use of national security intelligence practices for pandemic surveillance, states should consider the elements of Omand and Bellaby's frameworks. They need to balance just or sufficient cause, proportionality, intentionality, legitimate authority and turning to intelligence as a last resort. An ethical framework also needs to consider the prospect of success, as well as the discrimination of targets of surveillance. In addition to these considerations, any use of national security surveillance tools should be done in a transparent manner, with any subsequent data being used consistently within its purpose (the reason why it was collected) and in consideration of the aggregation problem.

\section{Conclusion}

The news is not all bad from a privacy and intelligence perspective. In some ways, modern technology has made health surveillance and reporting more private and real time than traditional methods of contact tracing and exposure notification. In some cases, no personal data is collected (e.g. in Germany, Canada and Vietnam) and a positive exposure results in a notification, rather than it being traced back to an individual contact, which has the obvious impact of informing a third party of the health status of an infected individual. In addition, concern over the expansion of national security surveillance has chilled uptake of disease tracking technologies in the United States (Berman, Fowler, and Roberts 2020, 1), and likely many other countries as well. When considering information sharing, Maxwell also raises questions about the legitimacy of state access to the private data of citizens in pursuit of the public good (Maxwell 2020).

When national security surveillance techniques are combined with health information, there is a strong potential for harms. On their own, national surveillance techniques certainly have risks, and the same can be said for health information. Combining these together creates greater potential for harms due to the sensitive nature of the information being collected, the intrusive means being proposed and the possibility of the information being used for a purpose other than just pandemic surveillance. It raises a host of potential issues including the involvement of national security agencies in health surveillance (where many of the proposed tools, techniques and analytic capabilities reside), information management, control, access and destruction and limits and sunset clauses on any of this proposed activity.

Surveillance systems are necessary to track (and eventually stop) the spread of infectious diseases, but those same systems can be used in discriminatory ways, 
such as by limiting freedom of movement and speech (Youde 2012, 83). This is true when national security surveillance tools are used and there are additional risks and vulnerabilities. The international community has a moral and international legal obligation to track the spread of the outbreak of an infectious disease and use any data collected in this process to benefit the general population (Youde 2012, 83).

It is not sufficient to simply ask IF something is legal; we should ask whether it should be and under what circumstances (Davis 2020). This is especially true in the case of pandemic surveillance, or really any extraordinary measures put in place in a time of crisis. We also need to acknowledge that it may be difficult or impossible to roll back or limit powers once in place and that sunset clauses and benchmarks are only a start (Davis 2020).

In the far past, pandemics transformed international politics but in more recent pasts, their effect on the international system has been more muted. Drezner argues that COVID-19's effects in this regard will be minimal (Drezner 2020, 14), although one area that may change is tolerance for surveillance. There has not been a widespread uproar about the use of national security surveillance technologies or tools, or other kinds of surveillance, by citizens, which implies that many may be willing to trade some aspects of privacy for the promise of increased security. Of course, the risk is that these technologies become a permanent feature of life (The Soufan Center 2020), even after the pandemic is over and COVID-19 spread is under control. Indeed, surveillance may, for some people, be preferable to movement restrictions, mask protocols and physical distancing requirements.

At the same time, in considering the prospect of national security surveillance for the COVID-19 pandemic, it is critical to remember the limitations of these tools and technologies. The "promise" of national security surveillance for the pandemic may have fallen short. National security surveillance involves tools and techniques that are largely targeted means of surveillance. While this has been of little use in the early stages of the pandemic, as the pandemic spreads, and perhaps comes more under control, these targeted measures may have more appeal and utility and may have particular appeal if a vaccine is not forthcoming or turns out to minimally effective.

It is also important to remember the enduring nature of emergency powers. Indeed, parallels can be drawn between the first six months of the global pandemic and the era immediately following the terrorist attacks of September 11, 2001, which saw significant broadening of state surveillance and intelligence powers around the world - powers that were never rolled back, and have instead become part of the fabric of the state intelligence and security apparatus. As we consider what, if any, national security surveillance tools and techniques should be deployed to combat the global pandemic, we would be wise to remember that privacy and civil liberties are hard-won rights, and yet are easily surrendered for the promise of economic prosperity, physical health and freedom of movement. The pandemic may yet force us to choose between these things. 


\section{References}

BBC News. 2020. "Russia Uses Facial Recognition to Tackle Virus". BBC News, April 3. www.bbc.com/news/av/world-europe-52157131.

. 2020a. "Coronavirus: Israeli Court Bans Lawless Contact Tracing". BBC News, April 27. www.bbc.com/news/technology-52439145.

. 2020b. "Coronavirus: Israel to Impose Three-Week National Lockdown". BBC News, September 13. www.bbc.com/news/world-middle-east-54134869.

Bellaby, Ross. 2012. "What's the Harm? The Ethics of Intelligence Collection". Intelligence and National Security 27 (1): 93-117. https://doi.org/10.1080/02684527.2012.6 21600.

Berman, Emily, Leah Fowler, and Jessica L. Roberts. 2020. "COVID-19 Surveillance”. SSRN Scholarly Paper ID 3666300. Rochester, NY: Social Science Research Network. https://doi.org/10.2139/ssrn.3666300.

Brading,Thomas.2020. "ArmyAnti-TerrorismTechnologyHelpsPinpointCOVID-19Cases". US Department of Defense (blog). May 13. www.defense.gov/Explore/News/Article/ Article/2185429/army-anti-terrorism-technology-helps-pinpoint-covid-19-cases/.

Davis, Jessica. 2020. "Intelligence, Surveillance, and Ethics in a Pandemic". Just Security, March 31. www.justsecurity.org/69384/intelligence-surveillance-and-ethics-in-a-pandemic/.

Drezner, Daniel W. 2020 “"The Song Remains the Same: International Relations after COVID19”. International Organization, 1-18. https://doi.org/10.1017/S0020818320000351.

Dunlop, Claire A., Edoardo Ongaro, and Keith Baker. 2020. "Researching COVID-19: A Research Agenda for Public Policy and Administration Scholars". Public Policy and Administration 35 (4): 365-83. https://doi.org/10.1177/0952076720939631.

Herman, Michael. 2013. Intelligence Services in the Information Age. Abingdon, UK: Routledge. https://doi.org/10.4324/9780203479667.

Kuo, Lily. 2020. “The New Normal': China's Excessive Coronavirus Public Monitoring Could Be Here to Stay". The Guardian, March 9. www.theguardian.com/world/2020/ mar/09/the-new-normal-chinas-excessive-coronavirus-public-monitoring-could-behere-to-stay.

Maxwell, Nick J. 2020. "Information Sharing in the Era of Coronavirus Tracing Apps: A New Context for Fighting Financial Crime?". RUSI (blog). August 11. https://rusi.org/ commentary/information-sharing-era-coronavirus-tracing-apps.

McCurry, Justin. 2020. "Test, Trace, Contain: How South Korea Flattened Its Coronavirus Curve". The Guardian, April 23. www.theguardian.com/world/2020/apr/23/testtrace-contain-how-south-korea-flattened-its-coronavirus-curve.

Omand, David. 2006. "Ethical Guidelines in Using Secret Intelligence for Public Security". Cambridge Review of International Affairs 19 (4): 613-28. https://doi.org/ 10.1080/09557570601003338.

Rosemain, Mathieu. 2020. "French Watchdog Warns against COVID-19 Smart Surveillance". Reuters, June 17. www.reuters.com/article/us-health-coronavirus-franceprivacy-idUSKBN23O2T7.

Sachs, Natan, and Kevin Huggard. 2020. "Technosurveillance Mission Creep in Israel's COVID-19 Response". Brookings (blog). June 9. www.brookings.edu/techstream/ technosurveillance-mission-creep-in-israels-covid-19-response/.

Shairani, Kaukab Tahir. 2020. "Will Pakistan's Mass Surveillance Strategy Outlive the Pandemic?". The Diplomat, June 5. https://thediplomat.com/2020/06/will-pakistans-masssurveillance-strategy-outlive-the-pandemic/. 


\section{Jessica Davis}

Sharwood, Simon. 2020. "Hong Kong Makes Wearable Trackers Mandatory for New Arrivals, Checks in with 'Surprise Calls' Too". The Register, March 19. www.theregister.com/2020/03/19/hong_kong_wearable_trackers_mandatory/.

The Soufan Center. 2020. "IntelBrief: Will COVID-19 Usher in the Era of the Surveillance Industrial Complex?". The Soufan Center (blog). May 8. https://thesoufancenter.org/ intelbrief-will-covid-19-usher-in-the-era-of-the-surveillance-industrial-complex/.

Yong, Ed. 2020. [etc.] “Long-Haulers Are Redefining COVID-19”. The Atlantic, August 19. www.theatlantic.com/health/archive/2020/08/long-haulers-covid-19-recognition-supportgroups-symptoms/615382/.

Youde, Jeremy. 2012. "Biosurveillance, Human Rights, and the Zombie Plague". Global Change, Peace \& Security 24 (1): 83-93. https://doi.org/10.1080/14781158.2012.641278. 